\title{
The Impact of the SARS-CoV-2 Pandemic on the Emergency Department and Management of the Pediatric Asthmatic Patient
}

This article was published in the following Dove Press journal:

Journal of Asthma and Allergy

\author{
Catalina Bover-Bauza (iD) ${ }^{1,2}$ \\ Maria Antonia Rosselló Gomila' \\ David Díaz Pérez (iD) \\ Aina Rosa Millán Pons ${ }^{3}$ \\ Jose Antonio Gil Sánchez ${ }^{1,2}$ \\ Jose Antonio Peña-Zarza l,4 \\ Joan Figuerola Mulet ${ }^{1,2}$ \\ Borja Osona iD ${ }^{1,2}$ \\ 'Division of Pediatric Respiratory \\ Medicine, Department of Pediatrics, \\ University Hospital Son Espases, Palma, \\ Balearic Islands, Spain; ${ }^{2}$ Multidisciplinary \\ Research Group in Pediatrics, Balearic \\ Islands Health Research Institute (IdISBa), \\ Palma, Balearic Islands, Spain; ${ }^{3}$ Department \\ of Statistic and Methodological Support, \\ Balearic Islands Health Research Institute \\ (IdISBa), Palma, Balearic Islands, Spain; \\ ${ }^{4}$ Research Group in Sleep Apnea and \\ Hypopnea Syndrome, Balearic Islands \\ Health Research Institute (IdISBa), Palma, \\ Balearic Islands, Spain
}

Introduction: Asthma exacerbation is among the commonest causes for pediatric emergency room visits, and respiratory viruses are frequent triggers of such exacerbations. Few studies have evaluated the consequences of the novel human coronavirus that causes the illness currently known as COVID-19, in the pediatric population.

Purpose: The objective of this study was to analyze the impact of the COVID-19 pandemic and lockdown measures on the emergency department in the pediatric asthmatic patient.

Patients and Methods: This retrospective observational study evaluated pediatric patients treated at the Pediatric Emergency Service for wheezing episodes. Changes in the number and characteristics of these patients over the same period of 2019 as compared to 2020 during the month following the alarm declaration (March 14 to April 15) were evaluated. Results: In total, data of 30 asthma patients managed in the period after the declaration of the coronavirus pandemic and of 158 asthma patients managed in the pre-COVID-19 period were included. In 2020, patient visits decreased by $82 \%$ in 2019 . No statistically significant differences among age, sex, oxygen saturation, fever status, or number of severe bronchospasm episodes were found. Nebulized medication usage was reduced significantly since the alarm declaration. No significant increase in requests for complementary testing in the COVID-19 period was found. No patient requiring hospital admission was found to be PCR SARS-CoV-2 positive. Median time spent in the emergency department decreased from 180 minutes in 2019 to 85 minutes in the COVID-19 era.

Conclusion: The COVID-19 pandemic and ensuing lockdown measures have led to an extraordinary reduction in emergency visits to the pediatric service. The ongoing pandemic has also led to improvements in the approach to asthma exacerbations and wheezing, to reduce the risk of exposure to the virus, such as increased use of pressurized metered dose inhaler and decreased time in the Emergency Department.

Keywords: COVID-19, pandemic, asthma, wheezing, children

\section{Introduction}

Acute respiratory pathology is among the most frequent causes for patient visits to the emergency room. ${ }^{1,2}$ Wheezing in early life is a common disorder, with approximately $50 \%$ of children suffering wheezing episodes in the first year of life. Recurrent wheezing is estimated to occur in one-third of preschool-age children and results in significant morbidity, more frequent utilization of health care services, and significant economic cost. ${ }^{3,4}$ Although causes of wheezing are various, recurrent wheezing is typically brought about by asthma. Respiratory viruses are well-known triggers of asthma exacerbations. ${ }^{5,6}$ Coronaviruses are respiratory
Correspondence: Catalina Bover-Bauza Division of Pediatric Respiratory Medicine, Department of Pediatrics, University Hospital Son Espases

Carretera Valldemossa 79, Palma, 07I20 Spain

Tel $+3487 / 205000$

Fax +34871909712

Email catalina.bover2@ssib.es
Journal of Asthma and Allergy 2021:14 101-108 
viruses that have been implicated in both upper respiratory infections and asthma exacerbations. Seven coronaviruses are currently known to cause disease in humans. The severe acute respiratory syndrome coronavirus 2 (SARSCoV-2), a novel human coronavirus, is understood to cause the illness currently referred to as COVID-19.,

The rapid global increase in COVID-19 cases prompted the World Health Organization (WHO) to declare pandemic status on March 11, 2020. Faced with a public health crisis of enormous magnitude a state of alarm was declared in Spain on March 14. As a result, strict measures such as mandatory house confinement and closure of schools were introduced.

As the main pathology of SARS-CoV-2 is an acute respiratory syndrome, its pathophysiological aspects, including influences on other disease processes, are extremely complex. Both the incidence and severity of SARSCoV-2 infection in the pediatric population have been less as compared to the adult population. Although this phenomenon has implied a low demand for urgent care and hospitalizations due to the virus, an increased theoretical risk of pneumonia or acute respiratory disease due to COVID-19 infection in a child suffering from asthma has been established. ${ }^{9-11}$ There has also been speculation regarding possible increased risk in patients receiving inhaled corticoids alone or in combination. However, few studies have studied the impact of this pandemic and confinement measures on pediatric patients suffering wheezing, seen in the emergency room.

We aimed to analyze the impact of the ongoing coronavirus pandemic as well as lockdown measures on the pediatric asthmatic population in the emergency department. Changes between the number and characteristics of these patients for the month following the alarm declaration in 2020 and of patients for the same time period in 2019 were evaluated by analysis of data from the pediatric service of a tertiary hospital.

\section{Patients and Methods Study Design}

A retrospective, observational study of pediatric patients treated at the pediatric emergency unit for wheezing episodes was carried out at the Son Espases University Hospital, the only tertiary hospital in the Balearic Islands (of Spain). The facility has 92 pediatric hospital beds and serves a population of approximately 180,000 children less than 15 years of age.
The first month since the declaration of the state of alarm in Spain (Royal Decree 463/2020 of March 14, 2020) was selected and compared with the same time period of 2019. Two patient groups were thus studied: one, which included patients seen from March 14 to April 15, 2019 (pre-COVID-19 era) and a second, which included patients seen from March 14 to April 15, 2020 (COVID-19 era).

Pediatric patients 15 or less years of age suffering wheezing, cough or respiratory distress assessed in the emergency department were studied. Patients diagnosed with bronchitis, bronchiolitis or asthma as per ICD-10 guidelines were included in this study. Patients affected by other respiratory pathologies not accompanied by wheezing on auscultation were excluded.

Utilizing the Hospital Sant Joan de Deu score for patients younger than 2 years and the pulmonary score for those older than 2 years, a severity level was assigned to each patient. ${ }^{12,13}$ Severity levels were also established according to oxygen saturation as defined by the Global Initiative for Asthma (GINA), where episodes with oxygen saturation $<90 \%$ in patients older than 5 years and $<92 \%$ in patients younger than 5 years are classified as severe. ${ }^{14}$

During the period analyzed there have been no problems of access to medication or discontinuation of asthma medications due to lack of supply in this country.

This study was approved by the Balearic Islands Ethics Committee (CEI-IB number IB 4230/20 PI). The research was carried out in compliance with the Declaration of Helsinki, and respecting the confidentiality and anonymization of patient data. Given the retrospective nature of the data and the number of patients, and in accordance with national legislation, the ethics committee approved the study with the waiver of informed consent.

\section{Data and Variables Analyzed}

Demographic and epidemiological characteristics, clinical data, treatments administered, and results of complementary tests were obtained from the electronic medical record system of our hospital. Episode severity was scored as described above. Duration and rate of hospitalization were also considered.

\section{Statistical Analyses}

A descriptive analysis of the study group was carried out using frequencies and percentages to detail qualitative variables and measures of central tendency and dispersion to detail quantitative variables. Normally distributed 
quantitative variables were expressed as mean \pm standard deviation, and variables without normality were described using median and interquartile ranges. Differences between groups were analyzed using the Student's $t$-test (in case of normality) or Mann Whitney U-test (in case of non-normality) for quantitative variables and the chisquared test or Fisher's exact test for qualitative variables. A value of $p<0.05$ was considered to indicate statistical significance. Data were analyzed using SPSS v.26 software.

\section{Results}

\section{Visits and Diagnoses}

A total of 484 COVID-19 era patients attended our pediatric emergency service, over the course of the study period as compared to 2972 patients over the same pre-COVID-19 era time period of 2019. In total, 128 COVID-19 era patients suffered respiratory pathology $(26.4 \%$ of total visits) as compared to 644 pre-COVID-19 era patients $(21.7 \%$ of total visits). Of the 128 COVID-19 era patients, 30 suffered asthma/bronchospasm $(6.2 \%$ of all emergency room visits), and 2 suffered bronchiolitis $(0.4 \%$ of total visits). In the pre-COVID-19 era, 158 patients suffered asthma/bronchospasm (5.3\% of all emergency room visits) and 16 suffered bronchiolitis $(0.5 \%$ of total visits $)$ of patients seen. Over the month after the alarm declaration, patient visits reduced by $82 \%$ when compared to the same period of 2019; visit rates decreased from 100 visits per 100,000 inhabitants in the pre-COVID-19 period to 18 visits per 100,000 inhabitants in the COVID-19 period. Visit frequency decreased significantly in the first week but remained stable over the following 3 weeks. Similarly, a $75 \%$ decrease in the patient admission rate was found when compared to the pre-COVID-19 era, with 3 patients admitted in 2020 as compared to 12 in 2019 (Figure 1).

\section{Demographic Characteristics and Clinical Presentation}

Analysis of demographic characteristics of both groups, detailed in Table 1, revealed no statistically significant differences in age, sex, oxygen saturation on arrival, fever status or number of patients with severe bronchospasm. Patients less than 3 years of age constituted the majority in both periods in ED visits (44.3\% in 2019 vs $36.7 \%$ in 2020 ; no statistically significant differences in both periods, $p=0.372$ ). Admission was more frequent in children of this age, less than 3 years of age (50\% in the
pre-COVID-19 era vs $100 \%$ in the COVID-19 era; without statistically significant differences, $\mathrm{p}=0.287$ ). Most patients attending hospital suffered mild or moderate exacerbations.

\section{Controller Treatment for Asthma}

The majority of these patients, who were seen in the ED, were not taking controller treatment for asthma previously ( $70.7 \%$ in the pre-COVID-19 era vs $78.1 \%$ in the COVID19 era). In the pre-COVID-19 period, asthmatic patients were managed with either inhaled corticosteroids (ICS; $21.8 \%$ ) alone, ICS in combination with a long-acting $\beta 2$-agonist (LABA; $0.6 \%$ ), a leukotriene receptor antagonist (LTRA; 1.7\%), ICS in combination with LTRA $(2.3 \%)$, or ICS in combination with LABA and LTRA (2.8\%). In the COVID-19 era, $12.5 \%$ of patients were managed with ICS, 3.1\% were managed with ICS in combination with a LABA, $3.1 \%$ were managed with an LTRA, and $3.1 \%$ were managed with ICS in combination with an LABA and an LTRA. No statistically significant differences were observed in the controller treatment for asthma between the period 2019 and 2020 .

\section{Diagnostic Test and Treatment}

Diagnostic test and treatment data are shown in Table 2. No significant increase in requests for complementary tests was detected in the COVID-19 period. The median time spent in the emergency room was 180 minutes in 2019 compared to 85 minutes in the COVID-19 era $(\mathrm{p}=<0.001)$. In the preCOVID-19 period, $7 \%$ of patients were required to stay in the short-stay observation unit as compared to $3.3 \%$ in the COVID-19 era. Twelve patients were admitted to hospital (4 of them to the intensive care unit) as compared to three patients in the COVID-19 era (no intensive care unit admissions). Of the 12 pre-COVID-19 patients, 7 underwent chest radiography, 8 underwent blood tests, and 8 underwent sputum culturing. Of the three COVID-19 era patients, two underwent chest radiography, two underwent blood tests, three underwent sputum culturing, and three underwent SARS-CoV-2 PCR testing (Table 3).

During the COVID era study period, five patients with positive SARS-CoV-2 PCR tests were admitted to our hospital, although none presented with wheezing. The SARS-CoV-2 PCR test was performed on one patient in our sample population and not on the remaining 26 patients seen in the emergency department. All three patients who required inpatient admission over the course of the study period were tested and all were negative. 


\section{A}

Visits rate for wheezing per 100,000 inhabitants, by group and year

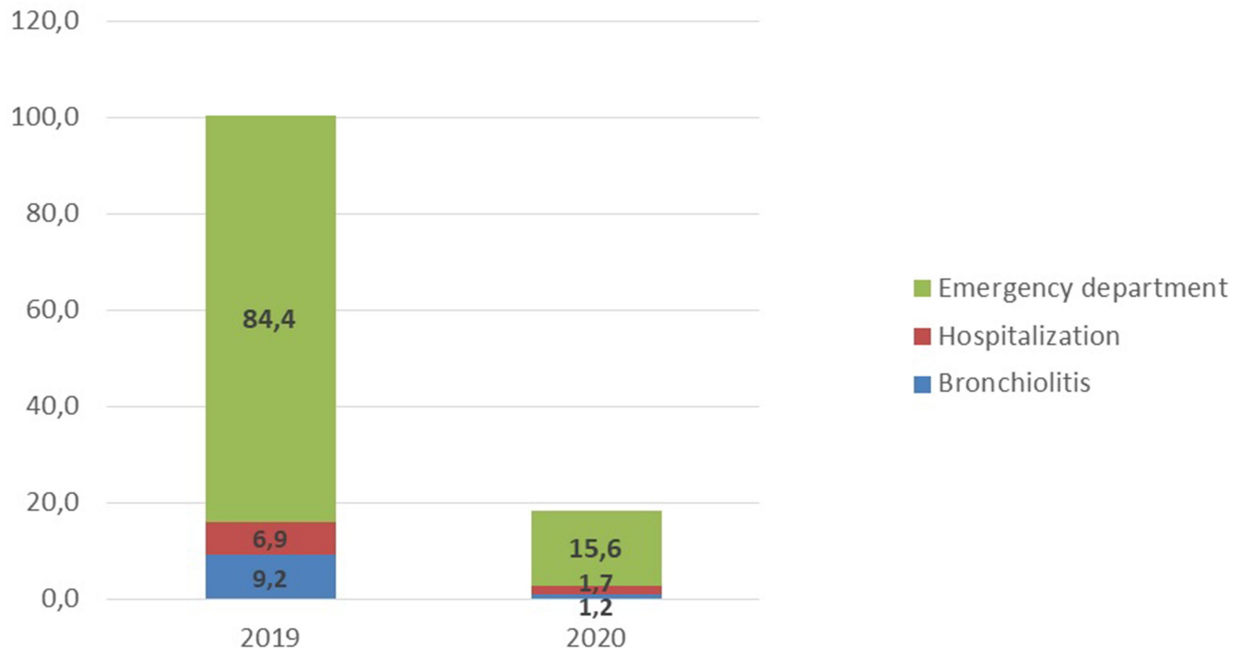

B

\begin{tabular}{|l|r|l|r|r|}
\cline { 2 - 5 } \multicolumn{1}{c|}{} & $\begin{array}{l}\text { 1st week } \\
\text { (March 14-21) }\end{array}$ & $\begin{array}{l}\text { 2nd week } \\
\text { (March 22-29) }\end{array}$ & $\begin{array}{l}\text { 3th week } \\
\text { (March 30-April 6) }\end{array}$ & $\begin{array}{l}\text { 4th week } \\
\text { (April 7-15) }\end{array}$ \\
\hline COVID19 CASES IN BALEARIC ISLANDS & 303 & 669 & 369 & 267 \\
\hline $\begin{array}{l}\text { NUMBER OF VISITS AT EMERGENCY } \\
\text { DEPARTMENT (ED) }\end{array}$ & 175 & 95 & 94 & 117 \\
\hline NUMBER OF VISITS AT ED WITH WHEEZING & 18 & \multicolumn{2}{|c|}{9} & 2 \\
\hline
\end{tabular}

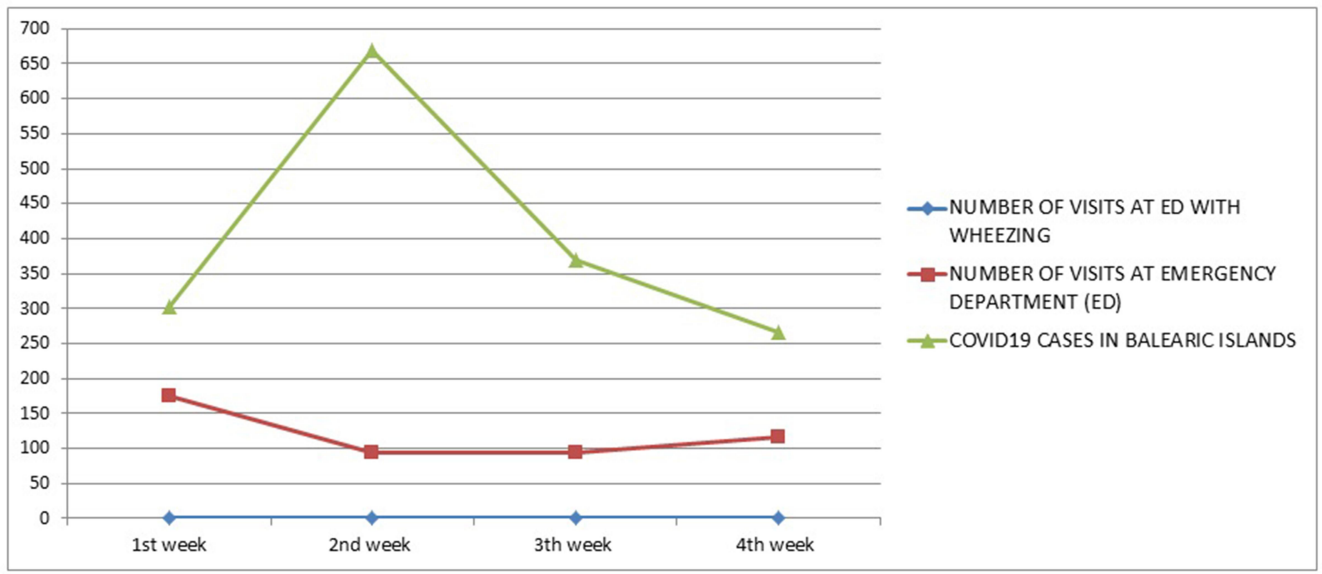

Figure I (A) Visit rate, (B) number of patients and patients with positive SARS-CoV-2 PCR. (A) the diagnoses asthma-emergency department, asthma-hospitalization and bronchiolitis are compared with these diagnoses of the previous year, but not between them. (B) ED: emergency department.

All patients diagnosed with asthma/bronchitis were treated with salbutamol. In the COVID-19 era, there was a notable decrease in emergency room salbutamol administration, with at-home regimens markedly more common in patients who had not been previously administered salbutamol in hospital (40\% indicated directly at home). In the pre-COVID-19 era $84.2 \%$ of patients were treated with nebulized salbutamol while only $23.3 \%$ were in the COVID-19 era $(\mathrm{p}=<0.001)$. Ipratropium administration was reduced from $49.4 \%$ in the preCOVID-19 period to $23.3 \%$ in the COVID-19 period $(p=0.009)$, although no changes were found concerning the use of other treatments or modes of respiratory support (Table 2).

\section{Bronchiolitis}

Hospital attendance by patients diagnosed with bronchiolitis decreased by $88 \%$ from the pre-COVID-19 period 
Table I Demographic and Clinic Characteristics

\begin{tabular}{|c|c|c|c|}
\hline & Pre-COVID-I9 & COVID-19 & $\mathbf{P}$ \\
\hline $\begin{array}{l}\text { Age } \\
\text { (median - interquartile range) }\end{array}$ & $3.8(1.4-7.5)$ & $4.1(1.7-8.7)$ & 0.593 \\
\hline $\begin{array}{l}\text { Group of age }(n \text { and } \%) \\
<3 \text { years } \\
3-6 \text { years } \\
>6 \text { years }\end{array}$ & $\begin{array}{l}70(44.3 \%) \\
34(21.5 \%) \\
54(34.2 \%)\end{array}$ & $\begin{array}{l}\text { II (36.7\%) } \\
10(33.3 \%) \\
9(30 \%)\end{array}$ & 0.372 \\
\hline $\begin{array}{l}\text { Sex ( } \mathrm{n} \text { and \%) } \\
\text { Male } \\
\text { Female }\end{array}$ & $\begin{array}{l}93(58.9 \%) \\
65(41.1 \%)\end{array}$ & $\begin{array}{l}18(60 \%) \\
12(40 \%)\end{array}$ & 0.907 \\
\hline FeveR ( $\mathrm{n}$ and \%) & $73(46.2 \%)$ & $16(53.3 \%)$ & 0.473 \\
\hline Previous inhaler treatment ( $\mathrm{n}$ and \%) & 51 (29.3\%) & 7 (21.9\%) & 0.390 \\
\hline $\begin{array}{l}\text { Oxygen saturation \% } \\
\text { (median - interquartile range) }\end{array}$ & $96(94-98)$ & $96.5(95-98)$ & 0.437 \\
\hline $\begin{array}{l}\text { Score (HSJD/PS) ( } \mathrm{n} \text { and \%) } \\
\text { Mild } \\
\text { Moderate } \\
\text { Severe }\end{array}$ & $\begin{array}{l}93(59.6 \%) \\
55(35.3 \%) \\
8(5.1 \%)\end{array}$ & $\begin{array}{l}\text { I4 (50\%) } \\
\text { I3 (46.4\%) } \\
\text { I (3.6\%) }\end{array}$ & 0.523 \\
\hline
\end{tabular}

to the COVID-19 period. Median patient age was 6 months in the pre-COVID-19 era (68.8\% male) as compared to 3.6 months in the COVID-19 era (100\% male). Illness severity was similar in both groups with oxygen saturation $>95 \%$ (median oxygen saturation $98 \%$ vs $96.5 \% ; p=0.772$ ). No patients required oxygen therapy, and the majority remained in the emergency department for 1-4 hours.

Table 2 Complementary Tests and Treatment

\begin{tabular}{|c|c|c|c|}
\hline & Pre-COVID-19 & COVID-19 & $\mathbf{P}$ \\
\hline \multicolumn{4}{|l|}{ Complementary tests } \\
\hline I. Chest Radiography & $36(24.7 \%)$ & $5(18.5 \%)$ & 0.625 \\
\hline 2. Blood test & $2(1.4 \%)$ & $0(0 \%)$ & 1 \\
\hline 3. Pharyngeal or nasopharyngeal culture & $4(2.7 \%)$ & I (3.7\%) & 0.577 \\
\hline 4. SARS-CoV-2 PCR test & $0(0 \%)$ & I (3.7\%) & \\
\hline \multicolumn{4}{|l|}{ Treatment } \\
\hline I. Salbutamol & & & $<0.001$ \\
\hline Nebulizer & $133(84.2 \%)$ & $7(23.3 \%)$ & \\
\hline Inhaler & $5(3.2 \%)$ & II (36.7\%) & \\
\hline Direct at home & $20(12.7 \%)$ & $12(40 \%)$ & \\
\hline 2. Ipratropium & 78 (49.4\%) & $7(23.3 \%)$ & 0.009 \\
\hline 3. Steroids & 89 (56.3\%) & $18(60 \%)$ & 0.710 \\
\hline 4. Antibiotic therapy & $31(19.6 \%)$ & $7(23.3 \%)$ & 0.891 \\
\hline \multicolumn{4}{|l|}{ 5. Respiratory support } \\
\hline With respiratory support: & $16(10.1 \%)$ & $2(6.67 \%)$ & 0.743 \\
\hline Oxygen (nasal or Ventimask) & 12 (7.59\%) & $2(6.67 \%)$ & \\
\hline OAF & $4(2.53 \%)$ & $0(0 \%)$ & \\
\hline VNI/VM & $0(0 \%)$ & $0(0 \%)$ & \\
\hline
\end{tabular}


Table 3 Results of Sputum Culturing and Chest Radiography

\begin{tabular}{|l|l|l|l|}
\hline \multicolumn{2}{|l|}{} & $\begin{array}{l}\text { Pre-COVID- } \\
19\end{array}$ & $\begin{array}{l}\text { COVID- } \\
19\end{array}$ \\
\hline Cultures & $\begin{array}{l}\text { Number of } \\
\text { cultures } \\
\text { Positive } \\
\text { Coinfection }\end{array}$ & 12 & 3 \\
\hline Results & $\begin{array}{l}\text { Rhinovirus } \\
\text { Parainfluenza } \\
\text { virus type 3 } \\
\text { Adenovirus } \\
\text { Coronavirus } \\
\text { NL63 } \\
\text { Metapneumovirus } \\
\text { Enterovirus } \\
\text { Bocavirus }\end{array}$ & 2 & 2 \\
\hline & 2 & 1 \\
\hline $\begin{array}{l}\text { Chest Radiography } \\
\text { (number abnormal/total } \\
\text { radiography) }\end{array}$ & $\begin{array}{l}\text { Emergency } \\
\text { department } \\
\text { Hospitalization } \\
\text { Bronchiolitis }\end{array}$ & $3 / 4$ & 0 \\
$1 / 2$ & $18 / 36$ & 0 \\
\hline
\end{tabular}

\section{Discussion}

This study analyzed respiratory episodes diagnosed with asthma/bronchitis in children who required hospital care after the implementation of coronavirus quarantine measures. During Spain's national lockdown, or the period from March 14 to April 15, significant decreases in pediatric emergency department visits and admissions for asthma/bronchitis episodes were found. Although it has not been analyzed in this study, in the following months a downward trend has also been noted, despite not being so marked, both in visits to the emergency room for asthma and in admissions for this reason.

The impact of the ongoing pandemic on ED in our hospital, of any cause, was also evaluated. ${ }^{15}$ During the first month of confinement, patient visits were reduced by $81.7 \%$ in the 3 healthcare areas: ED, pediatric hospitalization $(\mathrm{PH})$ and pediatric intensive care unit (PICU), compared to the pre-COVID-19 period. Visit rates decreased from 188.8 visits per 10,000 children in the pre-COVID-19 era to 34.5 visits per 10,000 children in the COVID-19 era. ED was the service with the most marked reduction $(-83.7 \%)$, where all diagnostic categories were reduced.

Despite this review in our hospital, studies investigating pediatric emergency care throughout this ongoing pandemic are scarce, as are studies concerning pediatric asthma management in the COVID-19 era. ${ }^{16}$ One prior study reported the effects of the COVID-19 pandemic on pediatric asthma, but it did not detail demographic characteristics or management strategies. ${ }^{17}$ The study reported a $76 \%$ drop in emergency department visits for patients suffering asthma of various severities in an American hospital since the declaration of pandemic status.

Similar $32 \%$ and $42.3 \%$ reductions in emergency department visits were also observed during the SARS (2003) and MERS (2012) outbreaks, but neither was as marked a change as that observed in the currently ongoing pandemic. $^{18,19}$ Asthma exacerbations were reported to have decreased during that time; this was attributed to improvements in hygiene measures. ${ }^{20}$ However, other nonepidemic coronaviruses cause infection of the respiratory tract and frequently result in asthma exacerbation. ${ }^{21}$

Regarding pediatric risk factors, the available case series to date from Wuhan evaluating hospitalized pediatric cases did not detail asthma as a pre-existing risk factor for morbidity or mortality. ${ }^{22}$ Although at the beginning of the pandemic there were no data, in recent months, studies have been appearing in the adult population. Muñoz et al found results in their study that support the idea that asthma does not appear to be a risk factor for the development of COVID-19, at least in hospitalized patients with more serious forms of infection. ${ }^{23}$

There are a number of potential explanations for the low asthma morbidity observed in the COVID-19 period. Throughout the currently ongoing pandemic, strict social distancing measures, school closures, and cessation of sport activities were implemented. In non-epidemic periods, common viruses were reported to cause $80-85 \%$ of reported asthma exacerbations in children aged 9-11 years old. ${ }^{21}$ It is thus understandable why the numbers of acute infections among children during the national lockdown were lower. On the other hand, the substantial decrease in visits to our emergency room may reflect the unwillingness of parents and caregivers to risk exposure to SARS-CoV-2.

In addition, the media, the Spanish Pediatrics Association and the Ministry of Health informed the general population in detail concerning a greater possibility of viral exposure in health centers while also urging people to avoid all non-essential medical visits.

A reduction in pollution during the lockdown is also a potential cause of decreased hospital visits by asthmatic patients. ${ }^{24} \mathrm{~A}$ number of studies have reported that monthly variations in several ambient air pollutants are associated with respiratory morbidity variations among school-age children. ${ }^{25}$ A lack of outdoor activities could have additionally resulted in lower exposure to seasonal allergens, such as pollens.

Despite increases in the severity of a number of pathologies since the declaration of the pandemic, possibly in 
part due to delays in medical care, wheezing episodes have not significantly changed in severity. ${ }^{26}$ In the present study, respiratory symptoms were not noted to be of greater severity as compared to prior to the pandemic period. Oxygen saturations likewise remained similar in both groups on initial patient presentation.

Several guidelines have been published on the management of pediatric asthma in the COVID-19 era. ${ }^{27}$ Treatment of asthmatic children with nebulizers throughout the currently ongoing pandemic has been suggested to increase the possibility of patient and caregiver exposure to crossinfection. Despite the efficacy of the pressurized metered dose inhaler (pMDI) when used with a spacer, in many countries, nebulizers continue to be used for the management of mild or moderate asthma exacerbation. Some guidelines, however, have suggested limiting aerosolized medications via nebulizers to mitigate infection risk. ${ }^{14,28}$ Thus, pMDI use with a spacer chamber should be implemented in hospital and nebulizer use reserved for administration in status asthmatics or children who do not respond to pMDI treatment. ${ }^{29}$

In this study, pMDI use was greater than that of nebulizers, when considering in-home use. This pandemic has improved the clinical utilization of the pMDI with spacer, which until recently was not commonly used in our hospital despite multiple previous recommendations. The change from nebulizer to pMDI management should be an important consideration for pediatricians in the interest of reducing risk for COVID-19 infection. Ipratropium administration also decreased in the COVID-19 era in conjunction with reduced nebulizer use, although its use with pMDI application in clinic did not increase. This phenomenon is likely due to attempts to minimize time and interaction with patients in the emergency room. A highly significant decrease in the average length of emergency room stays was also noted.

Despite the fact that a patient with SARS-CoV-2 infection may present with symptoms mimicking an asthmatic attack, few such cases undergo PCR testing, which contradicts the recommendations for this purpose. ${ }^{27}$ It is possible that some patients could have been infected by SARS-CoV -2 , but no increase in asthma severity was found and no admitted patients tested positive for this virus.

On the other hand, and although there is controversy concerning the influence of inhaled corticosteroids on the probability of SARS-CoV-2 infection, no significant impact on emergency room attendance of patients undergoing this treatment was found..$^{30}$
It is important to understand clinical trends and variations of pediatric asthma exacerbations in the COVID-19 era to make effective patient management in future outbreaks possible. Our findings thus not only help pediatric emergency and hospitalization services but also assist schools, health care professionals, and children better prepare for the fall asthma season.

This study had several limitations. First, it was a retrospective study and was carried out only in one center. Second, it is unclear if any pre-existing pathologies influenced asthma episodes in any way, or if patients had previously received telephone consultations with other healthcare professionals. Finally, analytical methods to address potential selection biases were not able to be used.

\section{Conclusions}

The ongoing COVID-19 pandemic, along with measures imposed to limit its spread, led to an extraordinary reduction in emergency care provided and admissions to the pediatric service at our hospital. Such changes have been more significant as compared to those arising during prior pandemics. This general reduction in the ED attendance could also explain the decrease in the assistance of the pediatric asthmatic patient. It remains important for asthmatic children to practice strict physical distancing, regular handwashing, and aeroallergen avoidance. The pandemic has led to important improvements in the approach to asthma exacerbations and wheezing in the emergency room, the application of which, in turn, reduces the risk of exposure to and infection by the coronavirus, such as increased use of pMDI and decreased time in the ED. Recommendations to avoid nebulized medication should be encouraged with changes in the latest guidelines clearly understood in order to improve patient management.

\section{Abbreviations}

ED, emergency department; ICS, inhaled corticosteroids; LABA, long-acting 32 -agonist; LTRA, leukotriene receptor antagonist; pMDI, pressurized metered dose inhaler; SARS-CoV-2, severe acute respiratory syndrome coronavirus 2; WHO, World Health Organization.

\section{Disclosure}

The authors declare no conflicts of interest for this work.

\section{References}

1. Zhou Y, Liu Y. Recent trends in current asthma prevalence among US adults, 2009-2018. J Allergy Clin Immunol Pract. 2020;S2213-2198 (20):6-30398. 
2. Centers for Disease Control and Prevention. Most recent national asthma data. Available from: https://www.cdc.gov/asthma/most_ recent_data.html. Accessed January 15, 2021.

3. Garcia-Marcos L, Mallol J, Sole D, Brand P, EISL Study Group. International study of wheezing in infants: risk factors in affluent and non-affluent countries during the first year of life. Pediatr Allergy Immunol. 2010;21(5):878-888. doi:10.1111/j.13993038.2010.01035.x

4. Mallol J, Garcia-Marcos L, Sole D, Brand P, EISL Study Group. International prevalence of recurrent wheezing during the first year of life: variability, treatment, patterns, and use of health resource. Thorax. 2010;65(10):1004-1009. doi:10.1136/thx.2009.115188

5. Sears MR. Epidemiology of asthma exacerbations. J Allergy Clin Immunol. 2008;122(4):662-668. doi:10.1016/j.jaci.2008.08.003

6. Wark PA, Tooze M, Powell H, Parsons K. Viral and bacterial infection in acute asthma and chronic obstructive pulmonary disease increases the risk of readmission. Respirology. 2013;18 (6):996-1002. doi:10.1111/resp.12099

7. Zimmermann P, Curtis N. Coronavirus infections in children including COVID-19: an overview of the epidemiology, clinical features, diagnosis, treatment and prevention options in children. Pediatr Infect Dis J. 2020;39(5):355-368. doi:10.1097/ INF.0000000000002660

8. Dong Y, Mo X, Hu Y, et al. Epidemiology of COVID-19 among children in China. Pediatrics. 2020;145(6):e20200702. doi:10.1542/ peds.2020-0702

9. Parri N, Lenge M, Buonsenso D. Children with Covid-19 in pediatric emergency departments in Italy. N Engl J Med. 2020;383:187-190. doi:10.1056/NEJMc2007617

10. De Ceano-vivas M, Martin-Espin I, Del Rosal T, et al. SARS-CoV-2 infection in ambulatory and hospitalised Spanish children. Arch Dis Child. 2020;105:808-809. doi:10.1136/archdischild-2020-319366

11. Centers for Disease Control and Prevention. Coronavirus disease (COVID-19): people at increased risk. Available from: https://www. cdc.gov/coronavirus/2019-ncov/need-extra-precautions/people-withmedical-conditions.html. Accessed August 8, 2020.

12. Balaguer M, Alejandre C, Vila D, et al. Bronchiolitis score of sant joan de déu: brosjod score, validation and usefulness. Pediatr Pulmonol. 2017;52(4):533-539. doi:10.1002/ppul.23546

13. Smith SR, Baty JD, Hodge D. Validation of the pulmonary score: an asthma severity score for children. Acad Emerg Med. 2002;9 (2):99-104. doi:10.1197/aemj.9.2.99

14. Global Iniciative for Asthma. Global strategy for asthma management and prevention; 2020. Available from: www.ginasthma.org. Accessed July 23, 2020.

15. Díaz Pérez D, Lorente Sorolla M, González Lago S, Osona B. Impacto de la pandemia por SARS-CoV-2 en la asistencia a urgencias e ingresos de un hospital terciario [Impact of the SARS-CoV-2 pandemic on the use of the emergency department and admissions in a tertiary hospital]. An Pediatr (Barc). 2020; S1695-4033(20)30456-2.

16. Lazzerini M, Barbi E, Apicella A, Marchetti F, Cardinale F, Trobia G. Delayed access or provision of care in Italy resulting from fear of COVID-19. Lancet Child Adolesc Health. 2020;4(5):e10-1. doi:10.1016/S2352-4642(20)30108-5
17. Kenyon CC, Hill DA, Henrickson SE, Bryant-Stephens TC, Zorc JJ. Inicial effects of the COVID-19 pandemic on pediatric asthma emergency department utilization. J Allergy Clin Immunol. 2020;S22132198(20)30586-9.

18. Paek SH, Kim DK, Lee JH, Kwak YH. The impact of middle east respiratory syndrome outbreak on trends in emergency department utilization patterns. $J$ Korean Med Sci. 2017;32(10):1576. doi:10.3346/jkms.2017.32.10.1576

19. Boutis K. The impact of SARS on a tertiary care pediatric emergency department. Can Med Assoc J. 2004;171(11):1353-1358. doi:10.1503/cmaj.1031257

20. Van Bever HP, Chng SY, Goh DY. Childhood severe acute respiratory syndrome, coronavirus infections and asthma. Pediatr Allergy Immunol. 2004;15:206-209. doi:10.1111/j.1399-3038.2004.00137.x

21. Thumerelle C, Deschildre A, Bouquillon C, et al. Role of viruses and atypical bacteria in exacerbations of asthma in hospitalized children: a prospective study in the nord-pas de calais región (France). Pediatr Pulmonol. 2003;35:75-82. doi:10.1002/ppul.10191

22. Sun D, Li H, Lu -X-X, et al. Clinical features of severe pediatric patients with coronavirus disease 2019 in Wuhan: a single center's observational study. World J Pediatr. 2020;16:251-259. doi:10.1007/ s12519-020-00354-4

23. Chhiba KD, Patel GB, Vu THT, et al. Prevalence and characterization of asthma in hospitalized and nonhospitalized patients with COVID-19. J Allergy Clin Immunol. 2020;146(2):307-314.e4. doi:10.1016/j.jaci.2020.06.010

24. Zhang R, Zhang Y, Lin H, Feng X, Fu T-M, Wang Y. NOx emission reduction and recovery during COVID-19 in East China. Atmosphere. 2020;11(4):433. doi:10.3390/atmos11040433

25. Millstein J, Gilliland F, Berhane K, et al. Effects of ambient air pollutants on asthma medication use and wheezing among fourthgrade school children from 12 Southern California communities enrolled in the children's health study. Arch Environ Health. 2004;59(10):505-514. doi:10.1080/00039890409605166

26. Velayos M, Muñoz-Serrano AJ, Estefanía-Fernandez K, et al. Influencia de la pandemia por coronavirus 2 (SARS-CoV-2) en la apendicitis aguda. An Pediatr. 2020;93(2):118-122. doi:10.1016/j. anpedi.2020.04.022

27. Abrams EM, Szefler SJ. Managing Asthma during Coronavirus Disease-2019: an example for other chronic conditions in children and adolescents. $J$ Pediatr. 2020;222:221-226. doi:10.1016/j. jpeds.2020.04.049

28. The Canadian Paediatric Society Practice Point. Paediatric asthma and COVID-19. Available from: https://www.cps.ca/en/documents/ position/paediatricasthma-and-covid-19. Accessed July 26, 2020.

29. Mei-Zahav M, Amirav I. Aerosol treatments for childhood asthma in the era of COVID-19. Pediatr Pulmonol. 2020;55(8):1871-1872. doi:10.1002/ppul.24849

30. Halpin DMG, Singh D, Hadfield RM. Inhaled corticosteroids and COVID-19: a systematic review and clinical perspective. Eur Respir J. 2020;55(5):2001009. doi:10.1183/13993003.01009-2020

new therapies. The manuscript management system is completely online and includes a very quick and fair peer-review system, which is all easy to use. Visit http://www.dovepress.com/testimonials.php to read real quotes from published authors.

\section{Dovepress}

open-access journal publishing original research, reports, editorials and commentaries on the following topics: Asthma; Pulmonary physiology; Asthma related clinical health; Clinical immunology and the immunological basis of disease; Pharmacological interventions and
Submit your manuscript here: https://www.dovepress.com/journal-of-asthma-and-allergy-journal 